mentary functions should be included and that they should be on a six- and not a seven-figure basis. The main reason for the latter recommendation was that it made linear interpolation possible within a reasonable compass, and it was defended on the grounds that, apart from certain specialist needs already adequately catered for, ordinary scientific and technological calculations would need higher accuracy only very rarely indeed. The result was "Chambers's Six-Figure Mathematical Tables", in two volumes. The volume now under review is essentially an abridged version of these, containing a selection of the more useful tables. Many users will find this collection adequate for their needs, and there is obvious convenience in a single volume, if its contents do indeed suffice.

Most of the pages have been taken direct from the two-volume edition, but some have been reset at a wider interval. As will be seen from a summary of the contents which is given below, the range of elementary functions is quite well covered, which was certainly not the case with the old 'Chambers'. Much more emphasis has been laid on natural than on logarithmic values, since the former are much more frequently required in these days of mechanical computation.

The main tables give common logarithms, logarithmic and natural trigonometric functions (with argument in degrees, minutes, and seconds), circular functions (argument in radians), exponential and hyperbolic functions, natural logarithms, inverse circular and hyperbolic functions, powers, roots, reciprocals, factors and factorials. Pages of formula relating to the functions tabulated, lists of series and integrals, formulæ and tables of coefficients for interpolation and for numerical differentiation and integration, and sundry conversion tables, are included, along with copious worked examples showing how the tables may be used most efficiently.

The tables are planned so that, in general, linear interpolation gives the greatest accuracy attainable from them, and in the main tables the appropriate proportional parts are provided at every opening. In the few ranges where the second difference correction cannot be neglected, the user's attention is directed to this fact by the printing of the first differences in italics. Bessel's formula for applying the necessary corrections is advocated, and tables of the values of the coefficients are given. Other cases where linear interpolation becomes difficult are met by auxiliary functions (for example, $s(x)=\log x-\log \sin x$ for small $x$ ). For slowly varying functions (and this includes most of the auxiliary functions just mentioned), so-called 'critical' tables are provided.

Apart from the refinements of typography and lay-out which one associates with the name of Dr. Comrie, one cannot fail to be impressed by the evidence of the thought given and the care taken to provide the user with the maximum of information in the minimum of space, and the maximum accuracy with the minimum labour. Almost every page contains some ingenious device-many invented by Dr. Comrie himself-directed to one or other of these ends. The book is well produced, and is bound so that it lies flat at any opening, a great convenience in use. It represents remarkable value for money.

This was the last of Dr. Comrie's projects which he was able to see completed. By it alone one can measure both his greatness as a maker of tables and the loss we have sustained by his passing. W. G. BiCkLey

\section{HUMANITY AND THE HELM}

\section{The Human Use of Human Beings}

Cybernetics and Society. By Prof. Norbert Wiener. Pp. xi+241. (London: Eyre and Spottiswoode (Publishers), Ltd., 1950.) 18s. net.

COME two years ago, Prof. Norbert Wiener pub$S$ lished a book on cybernetics, in which he developed the subject mathematically, mainly with the object of clarifying certain researches in communication-engineering, to which he has made notable contributions.

$\mathrm{He}$ now follows this up with a volume more specifically aimed at the layman, and naturally hopes that it will keep its bearing fair and square upon the target (however erratic that target's course may be), as all good cybernetical devices should.

The sub-title "Cybernetics and Society" is appropriate, although we are told much more about the latter than about the former. Steering committees have become accepted in twentieth-century affairs : cybernetics and the whole armoury of calculating machines are means (theoretical and existential) of performing many functions for mankind from without rather than from within. The perils of all this are manifest, and need little emphasis.

Once the outlook is grasped, the course of this book follows almost automatically: entropy, language, semantics, communications, industrial revolutions (two), and the voices of rigidity. That Prof. Wiener has a profound respect for the human being is of the essence of these pages, and on that score alone his work commands both respect and gratitude. What, however, is less obvious - and sometimes a little irritating - is whether or not he is referring specifically to his own country (the United States) or whether his edicts are meant to apply universally. There are several instances wherein one discovers only at the end of a long disquisition that its purpose all along has been strictly limited, whereas whole paragraphs read like sweeping generalizations.

Some of the more physical concepts are especially valuable. One is our natural tendency to concentrate upon the "islands' of decreasing entropy ("Let us eat and drink, for to-morrow we die", in fact), rather than upon the 'oceans' for which $S=k \log W$. Here 'Baltzmann' for Boltzmann (repeated in the index) is a deplorable slip, although the status of the Wärmetod needs some thought at the moment. This is on account of 'open systems' of thermodynamics recently investigated by Bertalanffy and others; they may turn out to be the thermodynamies of the biological world, and hence of major consequence for society and for cybernetics.

Prof. Wiener is forthright about educational matters. We all come under his lash; but the heaviest strokes are reserved for his own country. The present reviewer, however, would like to record his delight-in visiting Prof. Wiener's own institution on two separate occasions - in finding so much provision for the study of the humanities (in the midst of technics), and for the liberal arts; and again, there is the University of Buffalo, straining both its finances and its academic man-power in a noble effort to give individual teaching its highest expression. This, too, encourages the hope that all is not lost.

For the rest, Prof. Wiener's apocalyptic utterances will doubtless bide their time, for they speak of things perhaps unknowable as yet. F. I. G. RAwLins 